УДК 504.53.631.118

$10.17213 / 2075-2067-2020-3-49-55$

\title{
ОСНОВНЫЕ ДОМИНАНТЫ РАЗВИТИЯ ИННОВАЦИОННОЙ ДЕЯТЕЛЬНОСТИ В АГРОМЕЛИОРАТИВНОЙ СФЕРЕ
}

\author{
(C) 2020 г. Л. А. Александровская
}

Новочеркасский инженерно-мелиоративный институт имени А. К. Кортунова (филиал),
Донской государственный аграрный университет, г. Новочеркасск, Россия

Цель исследования заключается в исследовании основных доминант развития инновационной деятельности в агромелиоративной сфере.

Методологию исследования представляют отечественные фундаментальные и прикладные комплексы технических средств и технологических подходов мелиоративной науки. Вопросы, связанные с негативными природными явлениями и антропогенным влиянием на окружающую среду на агромелиоративных системах, наглядно освещены в трудах В.И. Беспалова, В.Н. Виноградова, А.Н. Геннадьевой, В.Л. Дмитриенко, Е. Б. Колбачева, Н. В. Комова, А. Н. Косолапова, Н. А. Кузнецова, П. А. Михеева, Н.А. Страховой, С. Г. Тяглова, В. Н. Шкура. Ими представлены конкретные научные технические разработки и новые технологии, обеспечивающие проведение последовательной интенсификации использования мелиорируемых земель.

Результаты исследования. Организация проведения междисциплинарных и межотраслевых исследований полного цикла, учитывающих специифику конкретных территорий, в частности, природу расположенных на них водных объектов. Разработка инновационных продуктов и технологий, обеспечивающих повымение продуктивности мелиорируемых земель и их адаптацию к изменению климатических условий.

Перспективы исследования заключаются в необходимости разработки технологий, направленных на обеспечение формирования высокопродуктивных агроландмафтов при помощуи инновачионного мелиоративного и водохозяйственного оборудования, использования ресурсо- и энергосберегающих модулей в процессе мелиоративного воздействия.

Ключевые слова: инноваџии; мелиоративная деятельность; агроландшафт; экологоориентированные технологии; эколого-экономическая эффективность; адаптивная направленность.

\section{BASIC DOMINANTS OF THE DEVELOPMENT OF INNOVATIVE ACTIVITY IN THE AGROMELIORATIVE SPHERE}

\section{(C) 2020 L. A. Aleksandrovskaya}

Novocherkassk Reclamation Engineering Institute named after A. K. Kortunov (branch), Donskoy State Agrarian University, Novocherkassk, Russia

The purpose of the study is to study the main dominants of the development of innovative activity in the agro-reclamation sphere.

The methodological base of the study is represented by domestic fundamental and applied systems of technical means and technological approaches of reclamation science. Issues related 
to negative natural phenomena and anthropogenic environmental influences on land reclamation systems are clearly illustrated in the works of V.I. Bespalov, V.N. Vinogradov, A. N. Gennadyeva, V.L. Dmitrienko, E. B. Kolbachev, N.V. Komov, A. N. Kosolapov, N.A. Kuznetsov, P.A. Mikheev, N. A. Strakhova, S. G. Tyaglov, V. N. Shkura. They presented specific scientific technical developments and new technologies that ensure the consistent intensification of the use of reclaimed land.

The results of the study. Organization of conducting interdisciplinary and intersectoral studies of the full cycle, taking into account the specifics of specific territories, in particular, the nature of water bodies located on them. Development of innovative products and technologies to increase the productivity of reclaimed lands and their adaptation to changing climatic conditions.

The research prospects are the need to develop technologies aimed at ensuring the formation of highly productive agrolandscapes using innovative reclamation and water management equipment, and the use of resource and energy-saving modules in the process of reclamation impact.

Key words: innovations; reclamation activities; agrolandscapes; ecologically oriented technologies; ecological and economic efficiency; adaptive orientation.

Введение. Инновационное развитие мелиорации как агропроизводственной отрасли предполагает необходимость реализации большого комплекса технологических, продуктовых и организационно-экономических инноваций. При этом основными сферами реализации технических инноваций являются совершенствование конструктивных особенностей мелиоративных систем, внедрение технологий ресурсосберегающего профиля, разработка новых образцов поливной техники. Реализация продуктовых инноваций связана с внедрением новых подходов к формированию структуры посевных площадей и севооборотов, а также совершенствованием форм и методов осуществления агротехнических мероприятий. Организационно-экономические инновации в мелиоративной сфере выражаются в форме мероприятий, которые направлены на совершенствование форм и методов взаимодействия сельскохозяйственных предприятий и водохозяйственных организаций, государственной поддержки мелиоративной деятельности, условий финансово-кредитного обеспечения участников мелиоративного процесса, совершенствование методов принятия решений, касающихся различных аспектов развития мелиорации.

Кроме того, важнейшее значение в современных условиях приобретает разработка и внедрение экологоориентированных инновационных решений, ориентированных на совершенствование процессов использо- вания природных ресурсов и охраны окружающей среды с помощью принципиально новых инструментальных средств и технологических процессов. Сущностное содержание подобных решений заключается в обеспечении на основе исследований, разработок и научно-технических достижений нового или усовершенствованного наполнения различных аспектов системы земле- и водохозяйственных отношений, позволяющего обеспечить эффективность и рациональность использования природных ресурсов в рамках реализации комплексного природоохранного подхода и ориентации на получение конечного продукта мелиоративной деятельности, характеризуемого такими параметрами, как высокая потребительская стоимость, экологичность и востребованность.

Разработка инновационных продуктов и технологий, используемых в мелиоративной деятельности, имманентно должна быть направлена на обеспечение формирования высокопродуктивных агроландшафтов при помощи инновационного мелиоративного и водохозяйственного оборудования, использовании ресурсо- и энергосберегающих технологий в процессе мелиоративного воздействия.

В подобном контексте важнейшую роль приобретает поиск наиболее адекватных местной специфике инновационных решений, позволяющих обеспечить наиболее эффективное взаимодействие природной и производственной подсистем. Таким об- 
разом, адаптивность выступает в качестве одного из важнейших условий реализации инновационных процессов в мелиоративной деятельности.

Адаптивная направленность инновационных технологий проявляется в возможности оперативно трансформировать отдельные параметры, приемы, звенья используемых новшеств, а также рационализировать распределение используемых ресурсов в соответствии со спецификой агромелиоративных систем, в рамках которых они используются (рисунок 1).

Цель адаптации инновационных технологий заключается в достижении параметров, позволяющих объекту эффективно функционировать в условиях перманентно изменяющейся внешней среды [6]. Использование адаптационного подхода обусловлено необходимостью обеспечить необходимые параметры управления мелиоративной деятельностью при не до конца известных параметрах управляемого процесса.

Применительно к задаче управления внедрением экологоориентированных инновационных технологий в мелиоративной деятельности адаптация призвана обеспе- чить улучшение либо поддержание существенных параметров биологических объектов в рамках определенных физиологических пределов при изменении процессов воздействия на окружающую среду посредством комплекса агротехнических воздействий при изменяющихся условиях работы.

Отметим, что если при использовании традиционных технологий сущностное содержание экологизации управления технологическими процессами заключается в обеспечении строгого соблюдения всех агротехнических требований к качественным параметрам и срокам проведения мелиоративных работ, поддержанию установленных технологических режимов сельхозмашин, то в рамках адаптивного инновационного подхода происходят качественные изменения как в контексте проведения новых агротехнических мероприятий, так и в смысле применения принципиально новых видов мелиоративных технических средств.

При этом принятие решений, основанных на изменении технологических процессов, связано с оценкой экономической эффективности и экологической целесообразности, что предполагает альтернативность

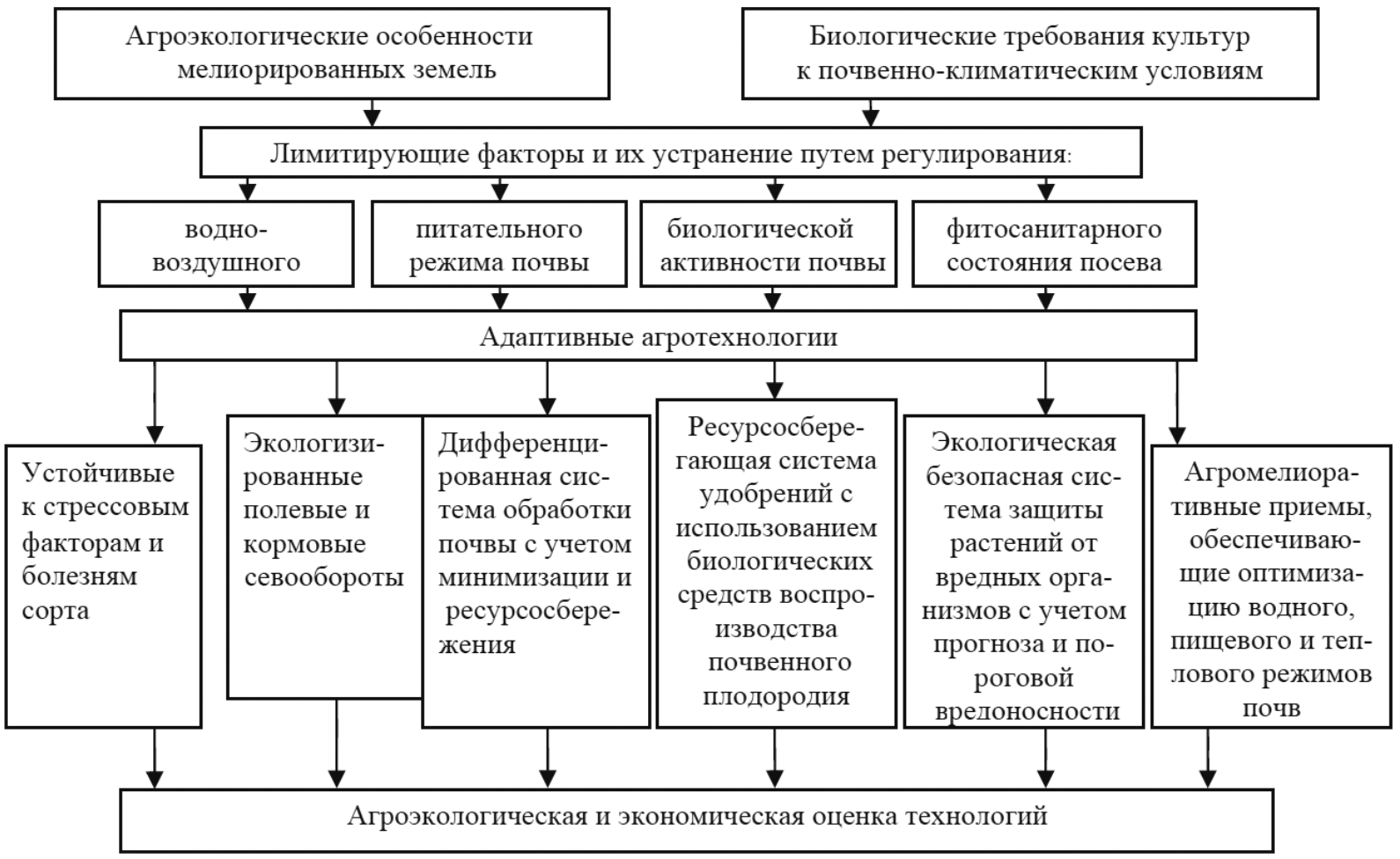

Рис. 1. Механизм реализации адаптивной направленности инновационных технологий в рамках агромелиоративных систем [2] 
выбора инновационных решений. В данном контексте эколого-экономический подход к решению проблем, связанных с внедрением инновационных технологий и технических средств, можно представить в виде адаптивной системы, функционирующей в условиях неопределенности и состоящей из следующих элементов:

1) оценка потенциальной экономической эффективности предлагаемой инновационной технологии;

2) оценка экологической эффективности в контексте снижения степени отрицательного воздействия мелиоративной деятельности на состояние окружающей среды;

3) системная оценка эколого-экономической эффективности инновационной технологии.

Сложность эколого-экономической оценки эффективности использования инновационных технологий во многом определяется тем, что она связана с анализом большого числа разнообразных аспектов экономической деятельности в совокупности с развитием определенных природных процессов, что находит свое проявление в следующих закономерностях сельскохозяйственного производства $[1,4]$.

1. Результативность функционирования сельскохозяйственных организаций в значительной степени определяется природно-климатическими условиями.

2. Одной из отличительных особенностей сельскохозяйственного производства является его сезонность.

3. Процесс сельскохозяйственного производства имеет очень длительный характер и не совпадает с рабочим периодом.

4. На ход протекания сельскохозяйственных процессов оказывают воздействие наряду с экономическими биологические, химические и физические закономерности, что обуславливает значительное усложнение оценки данного воздействия на результаты хозяйственной деятельности.

5. В качестве основного средства производства в сельском хозяйстве выступает земля, ключевые характеристики которой обусловлены природно-климатическими условиями.

Среди основных сфер реализации технических инноваций мелиоративного профиля можно указать на разработку и создание энергоэффективных оросительных систем нового поколения (например, деривационных систем, основанных на использовании энергии потока воды, создаваемой перепадами высот), противофильтрационных материалов, используемых при строительстве открытых каналов оросительных систем; дождевальных машин, предполагающих возможность индивидуального управления дождевателями с целью обеспечения равномерности увлажнения орошаемых земель; качественно новых технологий возделывания сельскохозяйственных культур на мелиорируемых землях, основанных на принципах точного земледелия; геоинформационных систем, математических моделей и программных инструментов, применяемых при строительстве и эксплуатации мелиоративных систем и использующих приборное и программное обеспечение дальнего зондирования Земли [7].

Отечественной фундаментальной и прикладной мелиоративной наукой разработан большой комплекс технических средств и технологических подходов, внедрение которых позволяет значительно увеличить производство сельскохозяйственной продукции, одновременно снизив техно- и антропогенную нагрузку на окружающую среду [5]. Однако вследствие недостаточной отлаженности системы производственной проверки и последующего внедрения инновационных достижений, а также отсутствия достаточных оборотных средств у значительной доли сельскохозяйственных организаций развитие инновационной деятельности имеет место лишь в некоторых достаточно крупных хозяйствах по отдельным направлениям мелиоративной деятельности.

В этой связи необходима привязка научных разработок к производственным нуждам мелиоративной отрасли, в связи с чем представляется целесообразным осуществление прикладных исследований как на федеральном, так и на региональном уровнях на основе согласованных между органами управления научной и агропроизводственной сфер планов проведения НИОКР, а также совместных планов производственной проверки и внедрения разработок в производство.

При реализации подобного подхода, по мнению специалистов, представляется необходимой реализация следующего комплекса мероприятий [8]: 
- усовершенствование методологии осуществления комплексного мониторинга плодородия почв сельскохозяйственных земель на основе использования более широкого перечня агрохимических, агрофизических и биологических параметров почвенного плодородия, что позволит повысить эффективность использования удобрений и других элементов систем земледелия;

- разработка параметров, характеризующих на основе использования расширенного набора показателей рациональный (оптимальный) уровень плодородия основных типов, подтипов и разновидностей почв в контексте учета требований выращивания важнейших сельскохозяйственных культур;

- осуществление необходимого для экономического и экологического обоснования внедрения инновационных систем земледелия комплексного мониторинга почвенного плодородия;

- активизация разработки технологических подходов, ориентированных на освоение земель с комплексным почвенным покровом, образуемым в результате антропогенной деятельности;

- разработка мелиоративных систем нового поколения, обеспечивающих более высокий уровень безопасности, надежности и ресурсосбережения;

- разработка опытных образцов и организация производства новой поливной и мелиоративной техники, соответствующей по своим ключевым характеристикам передовым зарубежным аналогам;

- разработка проблематики совершенствования процесса эксплуатации мелиоративных систем, автоматизации и телемеханики управления водораспределением, совершенствования метрологического обеспечения и т.д.

Что касается дальнейшего развития экоориентированных инновационных процессов в мелиоративной сфере, то, по мнению директора ВНИИ орошаемого земледелия В.В. Мелихова, в современных условиях наиболее актуальными направлениями научного обеспечения инновационного развития мелиоративной сферы являются [3]:

1) организация проведения междисциплинарных и межотраслевых исследований полного цикла, учитывающих специфику конкретных территорий, в частности, природу расположенных на них водных объектов;

2) разработка инновационных продуктов и технологий, обеспечивающих повышение продуктивности мелиорируемых земель и их адаптацию к изменению климатических условий;

3) получение консолидированных знаний и их широкая диффузия, в частности, при помощи сетевых форм взаимодействия с образовательными учреждениями, производственными и исследовательскими структурами;

4) развитие существующей и формирование новой научно-исследовательской инфраструктуры в контексте создания кластеров технологических платформ и других современных форм взаимодействия участников инновационной деятельности в мелиоративной сфере.

Заключение. Отмечая ключевое значение учета экологического аспекта при разработке и внедрении инновационных технологий в мелиоративной деятельности, необходимо сказать, что оно должно осуществляться с учетом следующих условий:

- обязательный учет почвенно-мелиоративных и природных факторов при инновационном обустройстве агромелиоративных систем;

- сохранение природных ландшафтов при формировании уникальных агромелиоративных территорий;

- необходимость следования нормативно-правовым требованиям, обеспечивающим эффективность использования земельных и водных ресурсов при внедрении новых технологических решений;

- повышение эффективности агромелиоративного производства на основе использования инновационных подходов должно обеспечивать темпы воспроизводства почвенного плодородия, ключевым критерием которого является наличие положительного баланса минеральных питательных веществ.

\section{Литература}

1. Александровская Л. А. Эколого-экономические аспекты обоснования использования земельных ресурсов в системе агромелиоландшафтов // Terra Economicus. - 2012. T. 10. 一 №2-2. - C. 80-83. 
2. Ковалев Н.Г., Полозова В.Г., Пушкина Л.В. Научное обеспечение адаптивной интенсификации сельскохозяйственного использования мелиорированных земель в Нечерноземной зоне России // Природообустройство. - 2016. - №4.

3. Мелихов B. В. Актуальные проблемы мелиоративной науки в стратегии управления водными ресурсами // Орошаемое земледелие. - 2017. - №3. - С. 4.

4. Санду И. С. Организационно-экономические основы инновационных процессов в сельском хозяйстве. - М.: Петит, 1998.

5. Ткачева O.А. Охрана земель в зоне влияния мелиоративных систем // Вестник Южно-Российского государственного технического университета (Новочеркасского политехнического института). Серия: Социально-экономические науки. — 2014. — №1. C. $138-142$.

6. Шальнев В.A. Ландшафтно-экологический подход и ландшафтно-адаптивные системы сельхозугодий // Горные и склоновые земли России. Пути предотвращения деградации и восстановления их плодородия. - Владикавказ, 1998. - С. 30.

7. Щедрин В.Н., Балакай Г.Т., Васильев С.M. Концептуальное обоснование разработки стратегии научно-технического обеспечения развития мелиорации земель в России// Научный журнал Российского НИИ проблем мелиорации. - 2016. - №4. - С.9-10.

8. Щедрин В.Н., Балакай Г.Т., Перельгин А.И., Докучаева Л.М., Андреева Т.П., Балакай Н.И. Стратегия инновационного развития мелиоративного комплекса России на период 2012-2020 годы. - Новочеркасск: Российский научно-исследовательский институт проблем мелиорации, 2011.

\section{Referense}

1. Aleksandrovskaya L.A. Ehkologo-ehkonomicheskie aspekty obosnovaniya ispol'zovaniya zemel'nykh resursov v sisteme agromeliolandshaftov [Ecological and economic aspects of justification of land use in the system of agroagricultural landscapes] // Terra Economicus. 2012. - Vol. 10. - №2-2. - Pp. 80-83.

2. Kovalev N.G., Polozova V.G., Pushkina L.V. Nauchnoe obespechenie adaptivnoi intensifikatsii sel'skokhozyaistvennogo ispol'zovaniya meliorirovannykh zemel' v Nechernozemnoi zone Rossii [Scientific support for adaptive intensification of agricultural use of reclaimed land in the non-Chernozem zone of Russia] // Prirodoobustroistvo [Environmental engineering]. — 2016. — №4.

3. Melikhov $V . V$. Aktual'nye problemy meliorativnoi nauki $\mathrm{v}$ strategii upravleniya vodnymi resursami [Current problems of land reclamation science in water resources management strategy]// Oroshaemoe zemledelie [Irrigated agriculture]. - 2017. - №3. - P. 4.

4. Sandu I.S. Organizatsionno-ehkonomicheskie osnovy innovatsionnykh protsessov $\mathrm{v}$ sel'skom khozyaistve [Organizational and economic bases of innovative processes in agriculture]. - Moscow: Petit, 1998.

5. Tkacheva O.A. Okhrana zemel' v zone vliyaniya meliorativnykh sistem [Land protection in the zone of influence of reclamation systems] // Vestnik Yuzhno-Rossiiskogo gosudarstvennogo tekhnicheskogo universiteta (Novocherkasskogo politekhnicheskogo instituta). Seriya: Sotsial'no-ehkonomicheskie nauki [Bulletin of the South Russian state technical University (Novocherkassk Polytechnic Institute). Series: Social and economic Sciences]. — 2014. №1. - Pp. 138-142.

6. Shal'nev V.A. Landshaftno-ehkologicheskii podkhod i landshaftno-adaptivnye sistemy sel'khozugodii [Landscape-ecological approach and landscape-adaptive systems of agricultural land] // Gornye i sklonovye zemli Rossii. Puti predotvrashcheniya degradatsii i vosstanovleniya ikh plodorodiya [Mountain and slope lands of Russia. Ways to prevent degradation and restore their fertility]. - Vladikavkaz, 1998. - P. 30.

7. Shchedrin V.N., Balakai G.T., Vasil'ev S.M. Kontseptual'noe obosnovanie razrabotki strategii nauchno-tekhnicheskogo obespecheniya razvitiya melioratsii zemel' v Rossii [Conceptual justification for the development of a strategy for scientific and technical support for the development of land reclamation in Russia]// Nauchnyi zhurnal Rossiiskogo NII problem melioratsii [Scientific journal of the Russian research Institute of land reclamation problems]. - 2016. №4. - Pp. 9-10.

8. Shchedrin V.N., Balakai G.T., Perelygin A.I., Dokuchaeva L.M., Andreeva T.P., Balakai N.I. Strategiya innovatsionnogo raz- 
vitiya meliorativnogo kompleksa Rossii na period 2012-2020 gody [Strategy for innovative development of the Russian land reclamation complex for the period 2012-2020]. - Novocherkassk: Rossiiskii nauchno-issledovatel'skii institut problem melioratsii, 2011.

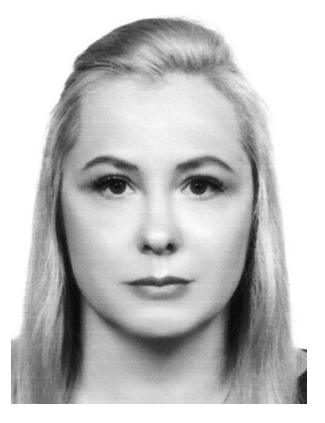

Александровская Людмила Анатольевна - кандидат экономических наук, доцент кафедры «Землепользование и землеустройство» Новочеркасского инженерно-мелиоративного института им. А. К. Кортунова.

Aleksandrovskaya Liudmila Anatolievna - Candidate of Economic Sciences, Associate Professor, Chair «Land Management and Land Tenure», Novocherkassk Reclamation Engineering Institute named after A. K. Kortunov (branch), Donskoy State Agrarian University.

346400, г. Новочеркасск, ул. Пушкинская, 111

111 Pushkinskaya st., 346400, Novocherkassk, Russia

E-mail: alika2007@rambler.ru 